\title{
A day in the operating room
}

$\mathrm{I}_{\mathrm{t}}^{\mathrm{t}}$ is another day in the operating room, and you have too much surgery booked. You cannot say that, or your last case will be cancelled. You may be able to finish at 3:30 if everyone has a sandwich or coffee in the hall, but will the union object? You do not explain why it is hard to stay on time or why you cannot predict how long surgery will take, because today one of your operations is complex and the time you will take will depend on who your nurses are and what you find when you operate. You know that at about 2:30 today, the dragon lady will appear over your shoulder to ask whether you will finish on time. You hedge a little if you know the time will be close. You know the administration hired her for the bottom line. She is the enforcer. The hospital can never run over budget. You know running late is an offense punishable by some vague but definite penalty, such as not being able to book surgery or losing operating room blocks. And you, not the petit bureaucrat who made the decision, will have to tell your last patient that surgery is cancelled.

These are just annoyances, and you have learned to live with them.

Today, you are lucky. You have a fast anesthetist who starts anesthesia efficiently. Your operating room has several nurses who only do plastic surgery. Paradise! You count your blessings. You know the plastic surgery nurse will make surgery faster because routines will be familiar. It is likely other nurses will be there too, because it makes nurse schedules easier. This can slow surgery, but is related to how technically demanding you are as a surgeon. If you can use simpler instruments and dressings you can save time, but you may have to compromise or decide which special things you want are not important to the result.

'Eliminate and streamline' is your new motto.

But you are obsessive...in a good way. This nature makes you slower even though you have told everyone what you need in advance, and have performed the same procedure in the same operating room before. You read that in Britain, surgeons were ranked for speed; faster surgeons getting higher marks, but faster surgeons ran two operating rooms simultaneously! So, you have two choices: change yourself or change your environment.

You realize that nurses are your best allies, and that they are caught in the same pressure cooker as you are. They have families and jobs they are intent on keeping. They cannot do anything

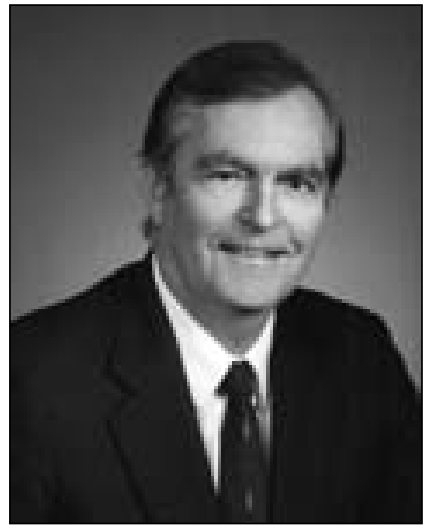

John R Taylor about surgical delays, so complaining to them does no good. They do not like the enforcer any more than you do. You realize that praising a good job well done helps everyone, so this becomes a habit. You find another solution for your dilemma.

Humour.

Humour is a solution in a difficult situation. Irony is a subtle self-mockery best used with yourself as the object of your fate. It is not cynicism, which is bitter, but rather a standing to one side, made by indirect but kind tongue-in-cheek observations. Irony does not seek everyone's understanding, only those primed for the same observation. Irony completes unformed thoughts, and provokes a smile for those who know something is not quite right, but are uncertain what that is.

Irony is an answer for those who take themselves seriously when they should be taking only their surgery seriously. Irony is a way of saying that no matter what anyone else says about what you have done, you at least are satisfied.

After all, what more can you ask?

John R Taylor 